\title{
Glycogen Storage Disease Type Ib
}

National Cancer Institute

\section{Source}

National Cancer Institute. Glycogen Storage Disease Type Ib. NCI Thesaurus. Code C122661.

Glycogen storage disease type I that is caused by mutations in the SLC37A4 gene. It is characterized by a deficiency of glucose-6-phosphate translocase. It may be associated with neutropenia resulting in recurrent bacterial infections, inflammatory bowel disease, ging ivitis, periodontal disease, and mouth ulcers. 